- 论坛・

\title{
细胞核和有性生殖是如何起源的?
}

\author{
谢 平* \\ (中国科学院水生生物研究所, 武汉 430072)
}

\begin{abstract}
摘要: 真核生物的起源是一个根本性的、令人生畏的进化谜题, 目前设想的关于“核”起源的流行情景还远谈不上 清晰。关于真核生物的起源可谓众说纷纭, 有共营模型、自演化模型、病毒性真核生物起源模型和外膜假说, 等 等。迄今为止, 真核演化的动因则鲜有涉及。笔者发现, 从原核生物到真核生物, 基因组的DNA总量大约增加了 3.5 个数量级, 而这与现代真核生物的DNA压缩比 (packing ratio)惊人地一致! 这样, 仅仅用偶然的吞潄、共生或寄 生来解释真核生物的起源, 无论如何是难以让人信服的(其实, 正是内共生理论将人们引入了歧途), 而关键是需 要解释基因组为何急剧增大。这可能与DNA的复制错误或多倍化现象不无关系, 当然并非完全排除不同种类个体 之间的侧向的基因流动或整合的可能贡献。不难理解，DNA压缩机制的成型应该就是迈向真核生物的关键一步， 自然还伴随了细胞内部的结构分化、更为精巧而复杂的细胞分裂机制的发展, 等等。因此, 本文提出细胞核起源 的新学说一一压缩与结构化假说。此外, 从分子遗传学的角度来说, “性”一点都不神秘, 就是将两个个体的基因组 拼在一起而已, 藉此种族多样的遗传信息分散到了个体之中; 而从生态的角度来看, “性”的原始动机就是与休眠 事件的偶联。
\end{abstract}

关键词：真核的起源; DNA；染色体；压缩比；压缩与结构化假说；有性生殖；休眠事件假说

\section{How did nucleus and sexual reproduction come into being?}

Ping Xie ${ }^{*}$

Institute of Hydrobiology, Chinese Academy of Sciences, Wuhan 430072

\begin{abstract}
The origin of eukaryote is a fundamental, forbidding evolutionary puzzle, and the popular scenarios of eukaryogenesis are far from being clear. So far, there have been various theories (e.g., syntrophic model, autogenous model, viral eukaryogenesis model, exomembrane hypothesis), but few explain why. I observed that $C$-value (the amount of DNA contained within a haploid nucleus) increased by 3.5 orders of magnitude from prokaryote to eukaryotes, which is inconceivably close to the packing ratio of DNA in extant eukaryotes. Thus, it is never convincing to explain eukaryogenesis solely by using accident phagocytosis, symbiosis or parasitism (the influential endosymbiont theory unfortunately took the wrong turning!), but what is important is to explain why genome increased so sharply. This may be mainly related to DNA replication errors or polyploidization, of course not completely ruling out the possible contribution from lateral gene flow or genetic integration between individuals of different species. It is above suspicion that successful packing of DNA (finally into chromosome) was a key step towards eukaryogenesis, of course also accompanied with structural differentiation in cell and development of more subtle and complex cell division, and so on. This paper presents "packing and structurization hypothesis" to explain eukaryogenesis. In addition, from a molecular genetic point of view, sexual reproduction is never a mystery as it is just a process to merge two individual genomes, by which diverse genetic information of the species are dispersed into its individuals. On the other hand, from an ecological point of view, the original motivation of "sex" was accidently coupled with dormancy.
\end{abstract}

Key words: eukaryogenesis; DNA; chromosome; packing ratio; "packing and structurization hypothesis"; sexual reproduction; accident dormancy hypothesis

收稿日期: 2016-02-28; 接受日期: 2016-07-12

* 通讯作者 Author for correspondence. E-mail: xieping@ihb.ac.cn 
真核生物是如何起源的? 这被认为是当代生 命科学的一个根本性的、令人生畏的谜题, 目前设 想的关于真核生物起源的流行情景(特别是所谓的 内共生途径)还远谈不上清晰(Koonin, 2015)。在光 学显微镜下可辨识的近似球状的核的存在被誉为 真核生物的最重要的标志, 但是, 关于核的起源机 制可谓众说纷纭(Martin et al, 2015; McInerney et al, 2015; Moreira \& López-García, 2015)。此外, 核与 “性”似乎难以分割, 因为核的出现伴随了生殖方式 的重大转变——有性生殖得到了空前的繁荣。遗憾 的是, 迄今为止, 人们并不真正知晓核和 “性” 是如 何起源的。遗传学家对 “性”的过程知道得已经十分 详细, 但他们(还包括进化生物学家)对“性”为何发 生以及为何如此广泛, 依然还是一头雾水(Hadany \& Comeron 2008; Schurko et al, 2008; Zimmer, 2009)。另一方面, 如果没有核, 亦不可能有“性”。 那么, 核与“性”到底是如何起源的呢?

\section{1 细胞核、 $C$ 值悖论与遗传模式}

\section{1 细胞核}

与真核生物相比, 原核生物显得十分小巧(无 论是细胞大小, 还是其遗传物质DNA分子), 内部 结构亦相对简单一一既见不到核，也见不到像线粒 体、叶绿体这样的细胞器(图1)。不难理解, 真核细 胞必须用大的体积来装填大的基因组, 对复杂的基 因组也需要进行更为有效有序的管控, 这可能导致 了细胞内部的模块化, 譬如, 将遗传物质集中分布 于用膜包裹的一个区域一一形成所谓的核。在细胞 核中, 还有 1 个或多个圆球形的核仁, 它是生产核 糖体的机器。在现代生物学中, 核被赋予了极为重 要的地位, 因为人们根据核的有无, 将生物界区分 为两大类——原核生物和真核生物。在植物细胞中, 有一个称之为叶绿体的细胞器专门用于光合作用。 原核和真核细胞在分裂方式上也呈现了很大差别, 前者是简单的二分裂(binary fission), 而后者演化出 了看似十分复杂的有丝分裂和减数分裂。在真核细 胞的有丝分裂过程中, DNA的变化可谓令人眼花缭 乱，它们浓缩(图1)形成数目不等的染色体(在同一 个种类中基本稳定), 整齐排列, 被一些细丝拉向两 极, 最后被均等地分配到子细胞中。而原核生物却 好像是在悄无声息之中快速地进行着DNA的拷贝 与分离, 以惊人的速度进行自我增殖。

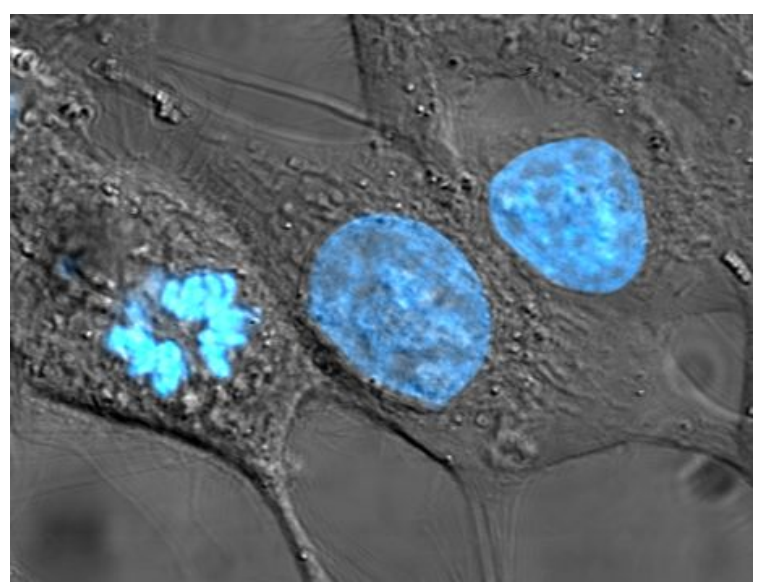

图1 用蓝色荧光染料染色的海拉细胞(HeLa cells)的核 DNA，中间以及最右的细胞处于细胞间期, 因此整个核被 标记, 而左边的细胞正在进入有丝分裂, 因此核DNA已经 浓缩(来源: 维基百科)

Fig. 1 Cultured HeLa cells have been stained with Hoechst turning their nuclei blue. The central and rightmost cells are in interphase, so the entire nuclei are labeled. The cell on the left is going through mitosis and its DNA has condensed (source: Wikipedia)

原核细胞是微小而简单的生物类群，几乎都以 单细胞的状态存在。而真核细胞支撑了各式各样复 杂的多细胞生命，包括我们人类自身。当然，真核 生物中也有很多以单细胞的形式而存在的, 如真核 藻类、原生动物, 等等。

不同真核生物之间染色体数目的变异也很大, 甚至同一个物种的雌雄个体之间亦会存在差异。染 色体的数目与生物的复杂性似乎也不一定必然相 关，譬如，简单的衣藻(Chlamydomonas)居然有17条 染色体，比果蝇(Drosophila melanogaster)还多1倍! 这说明染色体的增多并不一定与结构和功能的复 杂程度严格正相关，也许只是偶然的加倍罢了。

\section{$1.2 C$ 值悖论}

一般可用 $C$ 值 $(C$ value)来度量一种生物的基因 组的大小, 它指一种生物的单倍体基因组的DNA总 量。从总的趋势来看, 真核生物的 $C$ 值显著大于原核 生物。虽然真核生物的 $C$ 值变异很大, 但一般来说, 进化程度越高的类群, 群内最小 $C$ 值亦越大。但是, $C$ 值大小与其在进化上所处地位的高低或复杂性并 无绝对相关性, 譬如, 肺鱼的基因组远大于哺乳动 物, 而一些昆虫的基因组亦能大于哺乳动物, 这种 现象被称之为 $C$ 值悖论。这也说明，在演化历史中， 
基因组的变异具有相当的随机性。

\section{3 遗传模式}

染色体虽然承载了生命的绝大部分遗传信息, 但并非全部。譬如，细菌的质粒(plasmids)、真核生 物的叶绿体和线粒体也拥有自身的DNA, 虽然它们 与核DNA之间亦可能存在某种联系。此外, 像草履 虫(Paramecium)这样的原生动物, 还演化出两种类 型的核。

细菌可以含有质粒, 它是一种裸露的环状双链 DNA分子，属于染色体外DNA(extra-chromosomal DNAs), 可以含有具某些生理功能的基因。天然质粒 的DNA长度少则数千碱基对, 多至数十万碱基对。 质粒的复制独立于染色体，因此，在细胞分裂时可 能丢失掉。也因为如此, 一个细菌亦可能含单个质粒 的数百个拷贝, 而一个细胞里面亦可能有数种质粒 同时存在。质粒有时亦能整合到核DNA中去。

纤毛虫是一类单细胞的真核生物, 属于原生动 物门。纤毛虫有两种核, 一个多倍的大核 (macronucleus)和一个二倍的小核(micronucleus)。大 核提供营养生长所需的RNA(即控制非生殖的细胞 功能), 而小核包含了种系要向下一代传递的核物 质(但不表达基因)。纤毛虫既能进行二分裂式的无 性生殖, 也能进行有性生殖。二分裂时, 小核先进 行有丝分裂, 大核再进行无丝分裂, 然后细胞质从 中部横断, 成为 2 个新个体。进行结合生殖时, 交换 单倍的小核, 新的大核则从新的二倍小核发展而 成，而老的大核则被销毁掉(Prescott, 1994)。

值得注意的是, 原生动物的 $C$ 值跨度最大, 而 世界上最大的单细胞生物就在原生动物之中, 如最 近发现生活于极深大洋海底的一种被称为 xenophyophores的巨型阿米巴虫, 长度就超过了 $10 \mathrm{~cm}$ !

\section{2 关于细胞核起源的主要假说}

虽然人们对核的化学结构以及运作模式等已 经了解得相当清楚, 但关于核是如何起源的问题依 然仅停留于猜测。主要有4种假说, 但是还没有一种 得到广泛的认可(Pennisi, 2004)。

\section{1 共营模型(syntrophic model)}

该模型认为, 古菌与细菌共生导致了含细胞核 的真核细胞的诞生, 但是, 古菌与细菌均无细胞核 (Hogan, 2010)。共营模型认为, 与现代产甲烷古菌 类似的某些古老的古菌, 侵入并生活在类似于现代
粘细菌的细菌体内, 形成了早期的细胞核。古菌与 真核生物在特定蛋白质(如组蛋白)基因的相似性被 认为是支持以古菌为基础的细胞核起源理论的证 据。但笔者认为, 共营模型并不能回答核是如何产 生的问题。

其实, 共营模型类似于解释线粒体和叶绿体起 源的内共生理论(endosymbiotic theory)。Mereschkowsky (1905)提出叶绿体起源于内共生的猜想, 而 Ivan Wallin在1920s提出了关于线粒体起源的同样 的想法(Wallin, 1923)。之后叶绿体与线粒体内被发 现含有自己的DNA, 虽然绝大多数基因都已丢失。 譬如，核基因编码了超过 $98 \%$ 的线粒体蛋白质以及 超过 $95 \%$ 的叶绿体蛋白质，但要确定这些核基因有 多少是来自线粒体或叶绿体的祖先可能并不容易。 Margulis (1981)使内共生理论得到普及。她认为, 线 粒体内共生起源于一种原核生物对另一种原核生 物的攻击, 而不是所谓的吞饮(pinocytosis)或吞噬 (phagocytosis)作用, 因为这绝未在原核生物之间出 现过; 再者, 内共生的螺旋体形成了真核生物的鞭 毛和纤毛。此外, 线粒体的原始宿主是厌氧的还是 好氧的? 因为拥有复杂的氧化磷酸化系统，线粒体 应该是在好氧环境下长期演化的产物。因此, 如果 它的宿主是戻氧的, 那它至少通过与线粒体的共生 获得了对好氧环境更好的适应能力。

\section{2 自演化模型(autogenous model)}

该模型认为原真核 (proto-eukaryotic)细胞直接 自细菌演化而来, 并不需要通过内共生。证据来自 一类专性好氧菌一一浮霉菌(Planctomycete), 它们 具有清晰的胞内膜结构, 其中, 有一种被称为 Gemmata obscuriglobus的出芽菌, 其染色质被双层 的核膜所包裹(图2a), 类似于真核生物的核的结构, 而斯氏小梨形菌(Pirellula staleyi)的核被单层的细 胞质内膜ICM(图2b)所包裹(Fuerst, 2005)。但是，这 一模型并未进一步解释核是如何形成的。

\section{3 病毒性真核生物起源模型(viral eukaryogenesis model)}

该模型认为, 病毒感染原核生物导致了膜结合 的细胞核与其他真核生物特征的产生。证据是真核 生物和病毒在大分子结构上存在一定相似性, 譬 如，线性DNA链、mRNA的加帽，以及与蛋白质的 紧密结合(病毒的外套膜类似于组蛋白)。该假说的 一种观点认为，吞噬作用形成了早期的细胞“捕食 

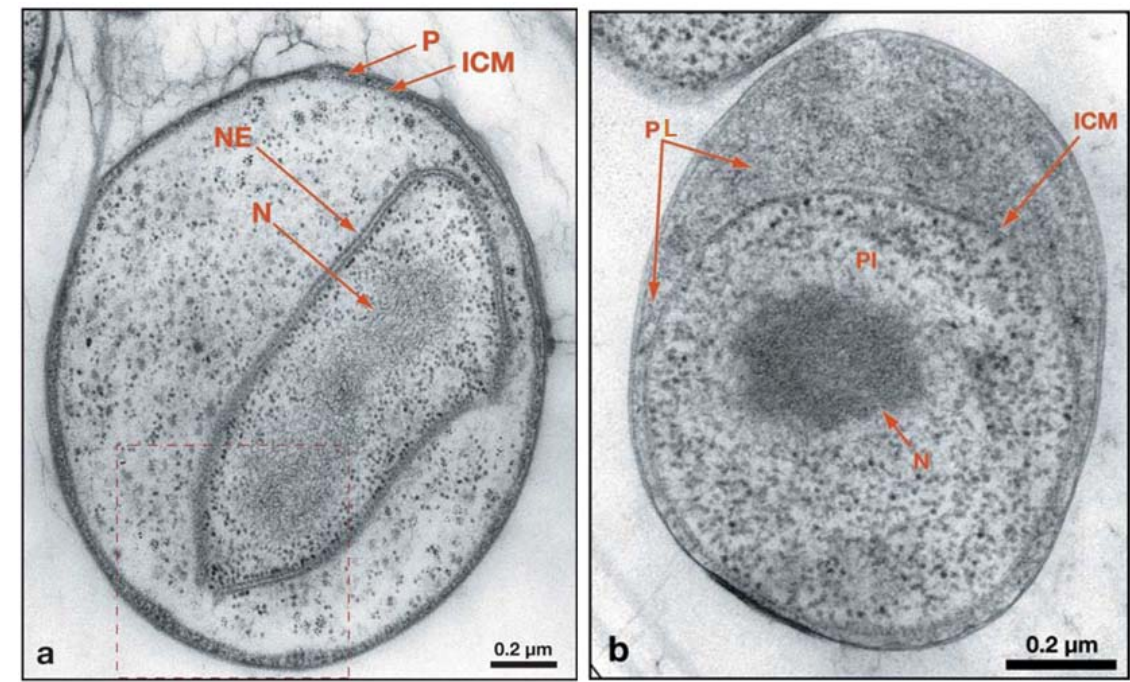

图2 通过冷替代方式固定和准备的Gemmata obscuriglobus(a)和斯氏小梨形菌(Pirellula staleyi)(b)的薄切片透射电镜图。NE: 核膜; N: 拟核; ICM: 细胞质内膜; P: 外室细胞质; PL: pirellulosome (小梨形菌属的一种膜细胞隔室) (引自Fuerst, 2005)

Fig. 2 (a) Transmission electron micrograph of thin section of Gemmata obscuriglobus fixed and prepared via cryosubstitution, showing the membrane-bound nuclear body with its nuclear envelope (NE) surrounding the nucleoid (N) and the more general features of the planctomycete cell plan, including the intracytoplasmic membrane (ICM) and paryphoplasm (P). (b) Transmission electron micrograph of thin section of cryosubstituted cell of Pirellula staleyi displaying compartmentalization into pirellulosome (PI) and P separated by the ICM. N is contained within the pirellulosome and thus compartmentalized and surrounded by the single ICM membrane (cited from Fuerst, 2005)

者”, 并随之演化出细胞核(Bell, 2001)。另一种观点 则认为, 真核生物起源于受到痘病毒感染的古菌, 因为现代痘病毒与真核生物的DNA聚合酶具相似 性(Villarreal \& DeFilippis, 2000; Takemura, 2001)。

\section{4 外膜假说 (exomembrane hypothesis)}

该假说认为细胞核是起源自演化出第二层外 细胞膜的单个早期细胞, 而包裹原来细胞的内膜则 转变成了核膜, 并逐渐演化出精巧的核孔结构, 以 便于将内部(如核糖体亚基)合成的物质送出核外 (de Roos, 2006)。

\section{3 真核借不来一一走出“内共生”的死胡同}

在各种细胞核起源理论中, “内共生”学说占据 着绝对的统治地位。冊庸置疑, 线粒体和叶绿体通 过内共生而来的设想已被越来越多的科学发现所 证实，但用同样的套路去设想核的起源，就误入了 歧途。Martin等(2015)发表了题为“Endosymbiotic theories for eukaryote origin”的综述论文, 在回顾了 过去的100多年间提出的用来解释真核细胞起源的 20 多种内共生理论后指出, 用内共生理论解释核的 起源依然存在很多问题: 它无法解释为什么核分室 与任何自由生活的细胞在如下几个方面是如此根
本性的不同: (1)生物合成或ATP驱动的生理过程(在 核分室都缺乏); (2)膜结构(无自由生活的细胞具有 类似的包裹方式); (3)通透性(无原核的胞液是通过 孔来与环境接触的); (4)分裂(在真核细胞开放的有 丝分裂时, 每分裂一次, 在表观上与质膜为同系物 的核膜的溶解)。当然，用于解释质体和线粒体的内 共生理论则没有这些问题。

在生物界，吞噬导致共生的现象可能客观存

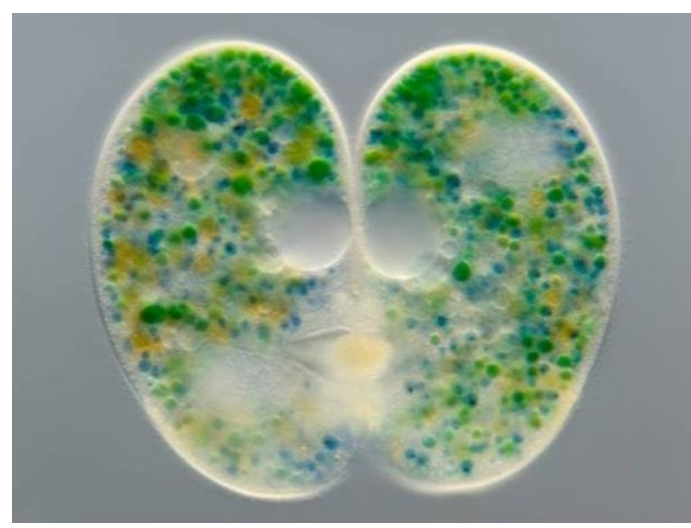

图3一种纤毛虫(Nassula ornata) 与藻类的共生现象 $(\times 160$ 倍)(来源: Wim van Egmond)

Fig. 3 Symbiosis of the ciliate Nassula ornata with algae (magnification:160×) (source: Wim van Egmond) 
在, 有些共生可能较为松散(一眼就能看出两者的 区别, 如图3), 有些共生甚至连痕迹都难以觉察到, 如真核细胞的叶绿体和线粒体。

但是, 按照一般的理解, 靠吞噬作用获得DNA 似乎是困难的, 因为如果能消化细胞壁, 那里面的 DNA也可能早就被破坏了。如果是这样的话, 那即 便是吞噬, DNA也应该是吞噬者的。那么问题就来 了, 吞噬者的核从何而来呢? 当然, 如果被吞噬者 幸运地存活下来, 情况可能就不一样了, 即一旦它 们与吞噬者形成了共生关系，两者之间的基因交流 或整合就有可能了。当然, 当两个不同物种形成寄 生关系时，亦可能发生类似的基因交流与整合。

此外, 像绿藻这样的真核藻类是如何形成的 呢? 即便假设吞噬者是真核的, 由于吞噬者应该是 动物性的, 那吞噬者的细胞壁是如何转化成绿藻这 样的植物性细胞壁的呢? 而植物和动物的细胞壁 是截然不同的。再退一步, 即便承认真核生物是一 种由吞噬、共生或寄生形成的不同物种的嵌合体, 也并未解决核的形成机制。迄今为止，几乎所有的 假说都停留于推测真核起源的可能途径, 而对演化 的动因则鲜有涉及。

依笔者之见，迄今为止的内共生假说的一个基 本特征就是主张 “核” 是借来的, 科学家大量的精力 都耗费在辩论“谁找谁借”, 证据主要依赖于一些分 子的相似性。“借”终究不是解决问题的办法, 因为 还得说清楚第一个核是如何出现的问题。就像生命 起源的宇宙胚种论最终还得面对第一个生命如何 产生这样的问题。内共生成核理论的最大问题就是 它对生命演化历程中基因组急剧增大的事实视而 不见。

\section{4 细胞核的起源一一压缩与结构化假说}

生命的演化伴随着基因组的扩增(复杂化)是不 争的事实, 特别是从原核演化到真核的过程。这如 何才能实现呢? 多倍化以及细胞之间遗传物质的 交流或重组可能是重要途径。譬如, 细胞分裂时, 如果染色体复制了但细胞未能分开, 就可能出现多 倍化(这样的过程依然还在自然发生, 且在人为的 诱导下快速地发生), 这也称之为同源多倍体 (autopolyploid), 而由不同物种杂交能产生异源多 倍体(allopolyploid)。在同一个细胞中, 不同DNA链 也可能会自动连接起来。
真核应该是基因组大型化的必然产物。如果细 胞将绝大部分DNA集中在被核膜包裹的区域就形 成“核”，它在细胞有丝分裂时期呈现独特的“染色 体”现象一一此时DNA高度聚集, 容易被碱性染料 (如龙胆紫和醋酸洋红)着色。而在分裂间期时, DNA 分散成细丝状，称之为染色质。

这样, 所谓真核, 就是细胞的绝大多数DNA集 中分布在这样一个区域，且十分致密，但它也依然 是一样性质的DNA。为什么真核要在核膜中? 也许 是一种秩序化管理的需要吧。在这里, 是速度和秩 序孰重孰轻的问题: 在简单的细菌那里, 速度优先; 而在复杂的真核生物那里, 秩序优先。细菌细胞由 于没有核膜, DNA的复制、RNA的转录与蛋白质的 合成可同时进行，而真核细胞的这些生化反应在时 空上虽然被分隔开来，但便于有序管控。然而，过 分强调核膜对真核生物演化的重要性就会迷失。此 外, 细菌的DNA没有内含子, 满足了快速复制的需 求。原核细胞演化出内膜系统, 不需要太大的奥妙, 因为, 生命最不缺少的就是膜, 生命的诞生之旅亦 是从膜开始的。

无论细胞分裂看起来多么复杂而神奇, 但本质 就是如何将承载遗传信息的DNA准确地分配到子 代细胞中去。随着生命从简单到复杂的演化, 基因 组的大型化在所难免, 其结果就是DNA链不断延 伸，这迫使DNA进行立体结构上的调整：(1)将DNA 集中在一定的区域并用膜隔离开来; (2)将长长的 DNA拆成若干段, 即若干染色体; (3)对链状DNA进 行压缩, 通过与组蛋白的合作, 成功压缩了很多倍, 看上去非常的致密。极端地说, 真核的形成过程就 是一种DNA的压缩过程！这是如何进行的呢?

染色体结合有两种蛋白质: 组蛋白 (一种低分 子量的碱性蛋白质)和酸性蛋白质。在真核细胞的有 丝分裂过程中，与组蛋白耦联的DNA分子的压缩能 力是十分惊人的(图4)。DNA双螺旋在每个组蛋白 8 聚体表面盘绕约 1.75 圈(长约 140 个碱基对)构成核小 体(nucleosome)。相邻核小体之间有长约50-60个碱 基对的DNA连接线，在相邻的连接线之间结合了一 个H1组蛋白分子。DNA似绳, 组蛋白似珠, 就像成 串的珠子一样, 这就是染色体的一级结构, 在这里, DNA分子大约被压缩了7倍。螺旋体是染色体的二 级结构, 每一周螺旋包括 6 个核小体, 这里的DNA 被压缩了6倍。螺旋体进一步螺旋化, 形成超螺旋 


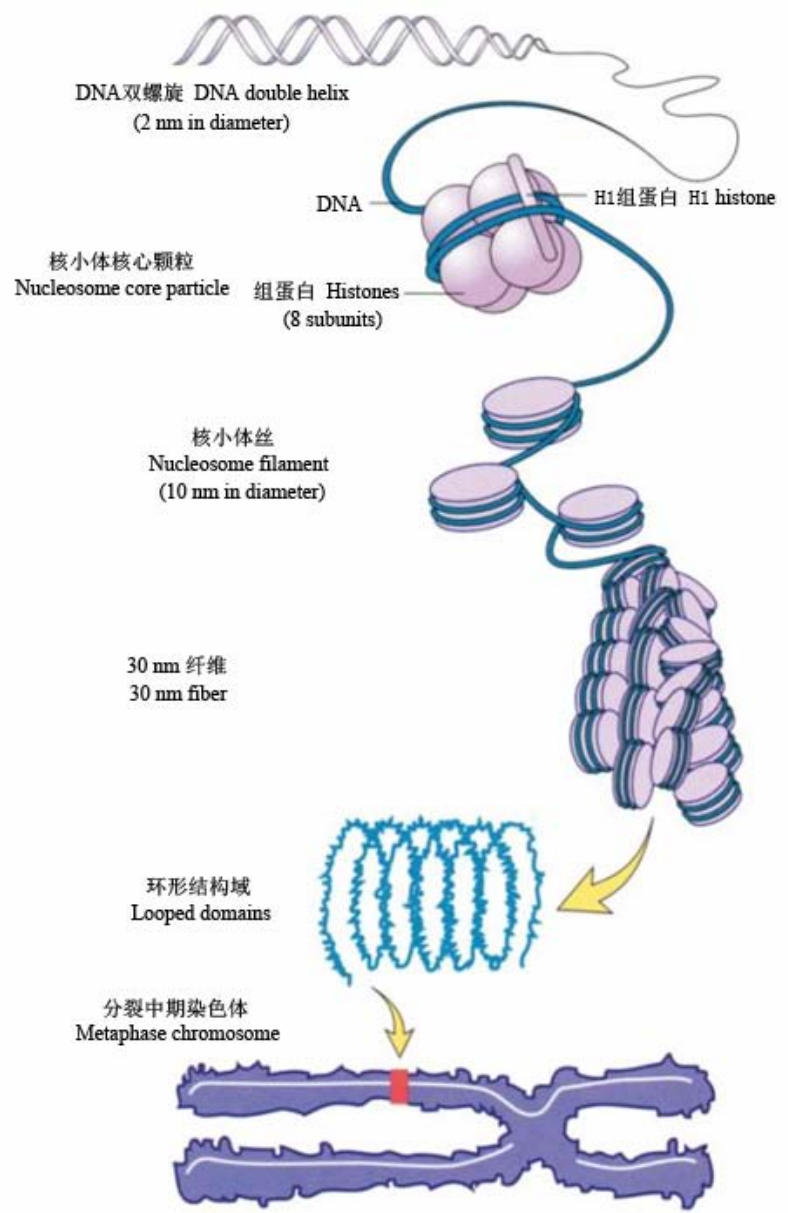

图4 DNA压缩成染色体的过程(来源: 百度图片)

Fig. 4 Compaction of DNA into chromosome (source: Baidu photo)

管，即染色体的三级结构，这里的DNA被压缩了 40 倍。超螺旋体再折叠盘绕形成染色单体(四级结构), 两条染色单体组成一条染色体, 这里的DNA又被压 缩了 5 倍。这样, DNA分子一共被压缩了 $7 \times 6 \times 40 \times 5=$ 8,400 倍!

再来看看这种DNA的压缩与基因组演化之间 的关系。细菌和古菌的 $C$ 值(单位 $\mathrm{pg}$ )的中位值约在 $10^{-3}-10^{-2}$ 之间，而真核生物约在1-10之间，高约 3 个 数量级。绝大多数 $C$ 值落于中位数 \pm 1.5 个数量级之 间。此外, 真核细胞约为原核细胞直径的 10 倍。若 考虑中位数及其上限偏移, 以及细胞直径 1 个数量 级的差异, 真核生物DNA的压缩倍数大约应该是 3.5 个数量级(图5), 笔者将此称之为真核生物DNA 的压缩原理(packing principle of eukaryotic DNA)。 这与现代真核生物的DNA压缩比(packing ratio)惊

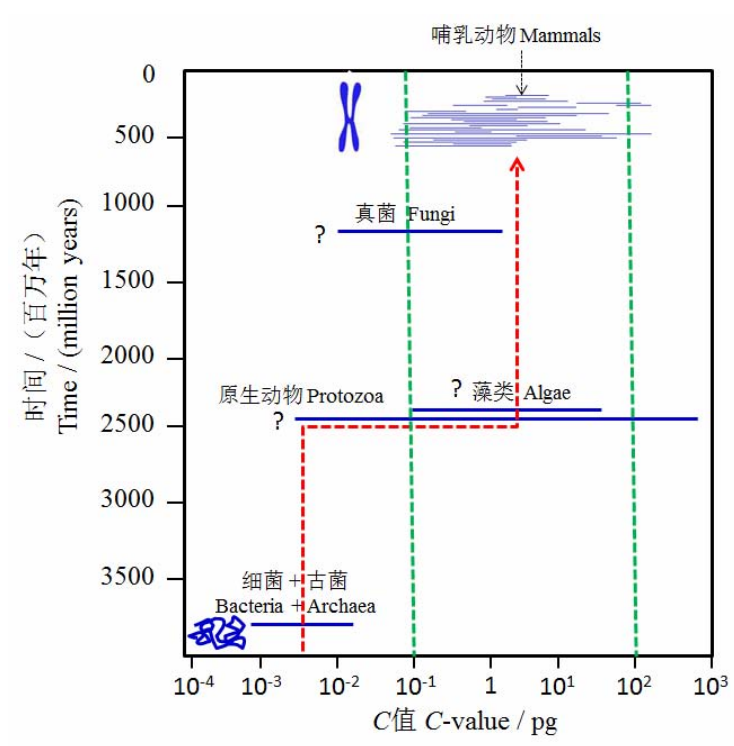

图5 根据各类生物的 $C$ 值推测真核生物DNA的压缩原理, 带箭头的红色虚线表示 $C$ 值中位数的演化轨迹, 绿色虚线表 示大多数真核生物 $\boldsymbol{C}$ 值的主要分布区间，问号表示该类生物 起源的年代仍然存在争议。C值引自Gregory (2004)。

Fig. 5 Packing principle of eukaryotic DNA based on " $C$ value" of various organisms. The dotted red line with an arrow indicates evolutionary track of the median " $C$ value", and the dotted green line shows the major range of the " $C$ value" of most eukaryotes. Question marks indicate uncertainity about the dates of their origins. $C$ values of various organisms are cited from Gregory (2004)

人地一致！譬如, 人的染色体中DNA分子伸展开来 的长度平均约为几个厘米, 而染色体被压缩到只有 几纳米长 $\left(1 \mathrm{~cm}=10^{7} \mathrm{~nm}\right)$ 。原核生物的 $C$ 值与真核生 物中的原生动物和真菌亦有交集, 特别是与原生动 物的交集更深, 这难道意味着它们可能就是真核生 物的祖先吗?

值得注意的是, 从 $C$ 值的中位数来看, 原核生 物与真核生物之间相差多达 3 个以上的数量级。因 此, 仅仅用一次偶然的吞噬、共生或寄生来解释真 核生物的起源无论如何是难以让人信服的, 而更关 键的问题是我们还需要解释真核生物的基因组为 何急剧增大了。这可能与我们熟知的DNA的复制错 误或多倍化现象不无关系，当然并非完全排除不同 种类个体之间的侧向的基因流动或整合的可能贡 献。不难理解，DNA压缩机制的成型应该就是迈向 真核生物的关键一步, 这自然还伴随了细胞内部的 结构分化、更为精巧而复杂的细胞分裂机制的发展, 等等。为了支撑大型真核细胞, 必须进行大量的革 
新，这被大量新基因的涌现所佐证(David \& Alm, 2011)。

从生态上来说, 蓝细菌光合放氧推进的大气氧 浓度的上升可能是复杂而耗能的真核生物出现的 重要前提, 因为与厌氧代谢相比, 有氧代谢的效率 大大提升, 而生命的复杂化需要这样的能量支撑。 因此, 吞噬、共生或寄生带来的生命复杂化可能仅 仅是一个小小的插曲，它们虽然是真实的，且不同 物种的DNA亦可能出现一定的整合, 但这依然难以 解释大小相差数个数量级的核的起源问题。

真核生物不会从天而降，它从更原始的原核生 物演化而来亦是不争的事实。而分子进化生物学家 长期纠结于真核生物到底源自真细菌还是古菌这 样的问题。他们通过基因组序列的比对发现, 真核 生物的一部分基因(如信息相关基因)与古菌相似, 而另一部分基因(如胞质功能基因)与真细菌相似, 因此认为真核生物源自真细菌和古菌的融合 (fusion)或内共生。但事实上, 所有的生物都具有一 个共同的祖先, 因此, 某一个后生物种均或多或少 携带有若干祖先物种的基因, 而这并不能意味它就 是由这些祖先物种融合而来的。况且, 不同微生物 之间的横向基因流动(lateral gene flow)方式众多且 十分频繁, 如果以地质年代而计, 这样的变异速率 是十分惊人的。依笔者之见，微生物其实就是一些 临时拼凑的物种，虽然这类研究并非毫无意义，但 至少对解释核的起源难以派上用场。试问, 对那些 被转来转去的基因, 我们如何知道谁才是它的原创 之主呢? 恕笔者直言, 试图用基因序列来确定所谓 原核生物的亲缘关系以及为此精心编制的算法或 故事或许只会是一种徒劳!

除了极少数的过渡类型外, 细菌没有核膜, 染 色体DNA一般为单环的不规则体，也称之为拟核 (nucleoid)。细菌的染色体DNA偶尔也有呈单线性的 (如博氏疏螺旋体Borrelia burgdorferi)。拟核主要由 DNA组成, 亦含有少量的RNA和蛋白质(它们好像 主要是mRNA和转录因子蛋白)。驱动核酸时空组织 的拟核相关蛋白(nucleoid-associated proteins, NAPs) 与真核的组蛋白完全不同，拟核的DNA结合蛋白不 形成核小体。

细菌在二分裂期间，复制完的子染色体分别移 动到细胞的相反的末端, 其机制还不甚清楚, 但蛋 白质可能将子染色体牵引到了细胞质膜的特定位
置(图6上)。在大部分真核生物中，在核外形成纺锤 体(spindle)，在有丝分裂期间，核膜溶解，微管将染 色体分离(图6下), 之后核膜重新形成。

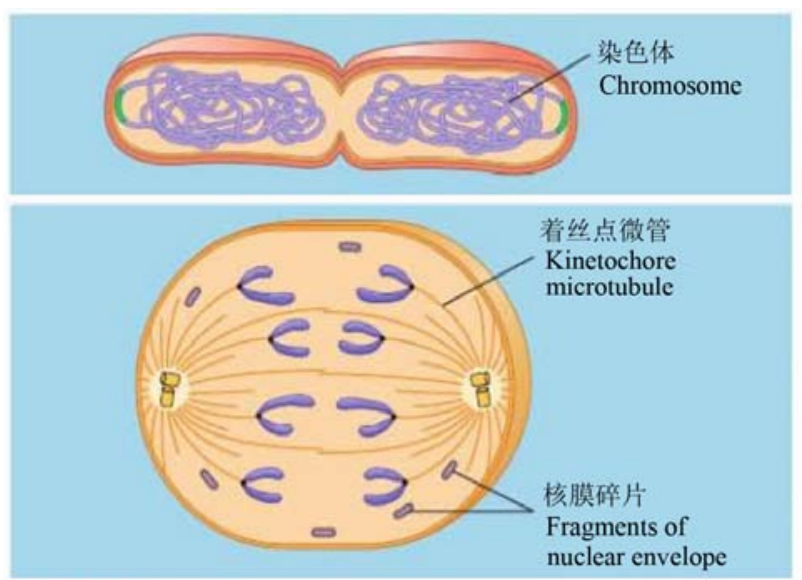

图6 原核(上图, 大肠杆菌Escherichia coli)和真核(下图)细 胞的分裂比较(引自Campbell \& Reece, 2008)

Fig. 6 Comparison of the cell divisions between bacteria (upper figure, the bacterium Escherichia coli) and eukaryotes (lower figure) (cited from Campbell \& Reece, 2008)

需要指出的是, 无论是原核还是真核细胞, 子 染色体都必须要借助特定的蛋白质针定到细胞质 膜上，这样才能将DNA正确地分配到两个子细胞中 去。只是在原核细胞中，这种机制较为简单，而在 真核细胞中，由于要将众多的染色体同时分开，因 此演化出了复杂的纺锤体结构, 但也是要连接到质 膜上。或者说, 在原核细胞中, 不需要那么复杂即 可。

在现存的生物中，能找到原核和真核之间的过 渡类型，可将它们视为细胞结构化过程的中间产 物。譬如, 浮霉菌门(Planctomycetes)(图2)和海绵杆 菌门(Poribacteria)的拟核被双层膜所包裹(类似于真 核), 且具有胞内膜结构 (intracellular membranebounded compartments)。

在这里，笔者提出一个关于细胞核起源的新的 学说一一压缩与结构化假说 (packing and structurization hypothesis), 源自基因组复杂化的诱导。在大 气逐渐氧化的背景下, 地球上的生命 (无论是形态 结构, 还是遗传信息)加速了从简单到复杂的演化 历程，可能主要由于DNA的复制错误或多倍化并在 一定程度上叠加了不同种类之间的各种侧向基因 
转移方式以及内共生融合(endosymbioticfusion)等 导致了一些原核细胞基因组的大型化。这一方面需 要骨架蛋白的强化来支撑更大的细胞体积, 同时通 过个体生存的随机性篮选, 细胞内部逐渐结构化, 从而形成了复杂的内膜系统——细胞器, 被膜包裹 的核及其在细胞分裂中的分离方式亦是这种结构 化的产物。核的成型及有丝分裂的出现主要是为了 满足将巨大的DNA分子准确地分配到子代中去的 需求, 这里, 如何将长链DNA有效地压缩(借助组 蛋白)成若干染色体以及如何将多个染色体同时分 离(借助纺锤体) 是核演化的关键。核膜的形成虽然 并非轻而易举, 但亦不会困难无比, 膜有多种可能 的来源, 譬如, 原核细胞分裂时DNA就得针定在细 胞膜上。其实, 生命就起源自膜耦联的光化学过程, 细胞亦能产生各种各样的膜(谢平, 2014)。从本质上 来看, 包括核膜在内的细胞内膜系统就是为了实现 对复杂生化系统进行秩序化管控, 或者说, 秩序化 是通过细胞内部的模块化得以实现的。

这虽然可视之为一种自演化模型, 但笔者在压 缩原理和结构化等的基础上，试图诠释核演化的动 因与本质。当然, 这里更多地是依赖于逻辑的推测, 还需要大量的实证支持。总体而言, 与生命和密码 子的起源相比, 所谓 “真核”的起源应该要简单 得多。

\section{5 有性生殖起源——休眠事件假说(acci- dent dormancy hypothesis)}

为什么有性? 这样一个看似简单的问题不仅 令达尔文困惑不已, 150 年过去了, 人们都还未找到 一个普遍认可的理论, 这也被称为是进化生物学问 题之皇后“queen of problems in evolutionary biology” (Bell, 1982)。法国著名的遗传学家、诺贝尔生 理学或医学奖(1965年)获奖者Jacob (1998)在其专著 《鼠、蝇、人与遗传学》一书中感叹道: “在通过有 性方式来进行生殖的生物中, 一切都被安排得要使 同一物种的全部个体(除了真正的孪生个体)都互有 差异。这就犹如整个地球上起作用的遗传系统已被 调节得要永远产生差异。因此就有了这个悖论: 一 方面, 所有显得十分不同的东西, 归根结底却是很 相似; 另一方面, 所有显得十分相似的东西, 事实 上却是相当不同”。《为什么要相信达尔文》一书的 作者Coyne (2009)感叹道: “为什么会演化出性别
来？这其实是演化论最大的谜团之一”。

眼花缭乱的“性”令生物学家、哲学家以及庶民 百思不得其解, 从古延续至今。但从分子遗传学的 角度来说, 性一点都不神秘, 就是将两个个体的基 因组拼在一起而已一一每个体细胞都是 $2 \mathrm{n}$ 的, 只是 到了生殖细胞的时候, 通过减数分裂将 $2 n$ 变成 $n$, 即精子 $(n)$ 和卵子 $(n)$, 而它们融合后又恢复了 $2 n$ 。虽 然这就是一个简单的加减法, 但这件事情却意义非 凡, 即种族的遗传信息(包括变异)分散到了个体之 中, 而且任一个体的性状必定受到双亲遗传信息的 影响, 都是一种遗传重组。

当然, 在原核细胞那里, 个体之间偶尔也能进 行遗传物质 (DNA) 的交流, 如结合 (conjugation) 一一通过性菌毛介导的两个细胞之间的DNA 转移(图7)、转导(transduction)——病毒亦能介导细 菌细胞之间的DNA片段(染色体片段或质粒DNA) 交换, 等等。但真核生物的遗传重组变成了其生活 史中的一个固化环节。在一些低等动植物那里, 无 性繁殖依然是占绝对优势, 有性生殖只是产休眠卵 时才启用; 而在高等动植物那里, 有性生殖占据了 绝对的优势, 特别是哺乳动物只剩下了有性生殖, 这时也不是为了产休眠卵(因为是胎生的)。

笔者之前提出了关于有性生殖起源的休眠事 件假说(谢平, 2013)。至于为何是与休眠联系在一起 的, 这不得而知。这大概是一种偶然事件吧, 即二 个单倍体细胞融合在一起, 成为一个合子 $(2 n)$, 而 这个事件恰好又与休眠联系在一起了, 并获得了大 自然的青睐。在低等动植物中可以找到很多这样的 例子。相信未来一定有人能揭开这一事件的分子机 密。

酵母(Saccharomyces cerevisiae) 可以视为原始 的单细胞真核生物进化出具有简单两性生殖交替 生活史的一个例子(图8)。酵母是一种结构相对简单 的单细胞真核生物, 当不良环境来临时, 出现有性 生殖, 即通过二个细胞的融合产生子囊孢子。这种 子囊孢子的特化程度较低, 居然还能进行无性的出 芽生殖, 这是非常特别的现象。

之所以认为酵母的子囊孢子是原始的休眠体, 一是它的特化程度低, 二是它还能通过无性方式再 产生出子囊孢子, 而其他一些单细胞真核生物(如 藻类)的厚壁孢子一般是不可能再通过无性生殖产 生出新的厚壁孢子的。 
1.

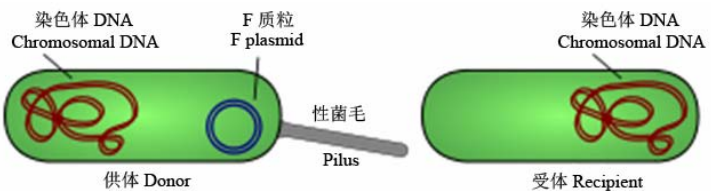

2.

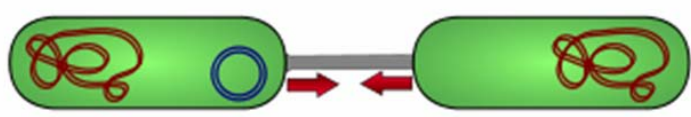

DNA聚合酶 DNA polymerase

3.

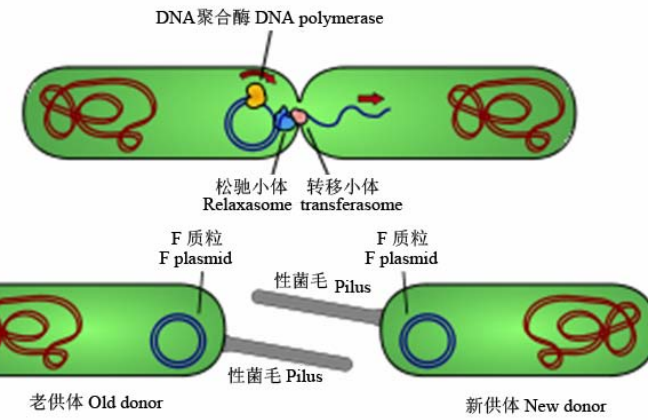

图7 细菌结合示意图。1: 供体细胞产生性菌毛; 2: 性菌毛 接触受体细胞, 使两个细胞连接在一起; 3: 能移动的质体 被切开, 一个单股的DNA被转移到受体细胞; 4: 两个细胞 质粒重新环化，合成第二股链，产生性菌毛，两个细胞又称 为活性的供体(来源: 维基百科)。

Fig. 7 Schematic drawing of bacterial conjugation. Conjugation diagram. 1, Donor cell produces pilus; 2, Pilus attaches to recipient cell and brings the two cells together; 3 , The mobile plasmid is nicked and a single strand of DNA is then transferred to the recipient cell; 4, Both cells synthesize a complementary strand to produce a double stranded circular plasmid and also reproduce pili; both cells are now viable donors (cited from Wikipedia).

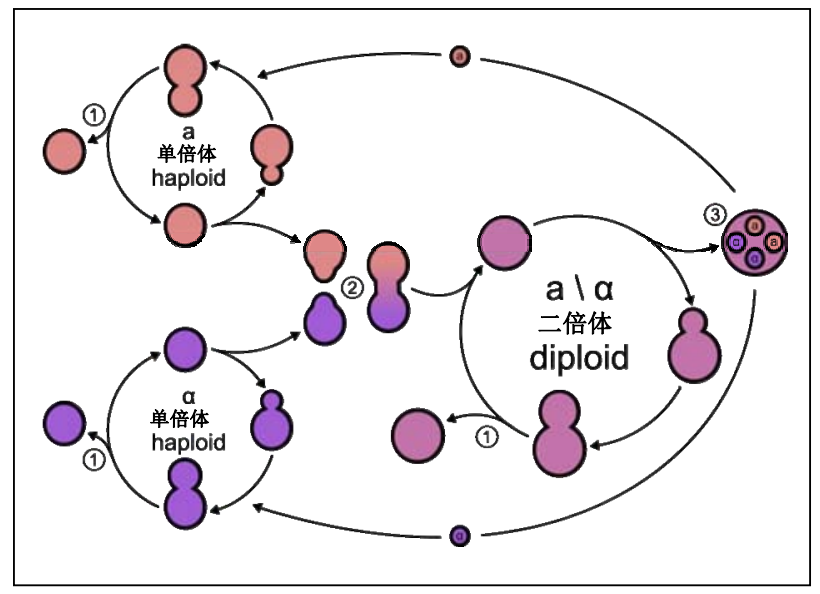

图8 酵母的生活史。(1)出芽生殖; (2)细胞融合; (3)孢子(引 自Wikipedia)

Fig. 8 The yeast cell's life cycle. (1) Budding; (2) Conjugation; (3) Spore. (cited from Wikipedia)
譬如，一种具有鞭毛的单细胞低等植物——衣 藻(隶属于绿藻门)便是如此(图9)。环境适宜时, 衣 藻连续进行无性生殖, 单倍体的游动孢子通过有丝 分裂, 产生出新的单倍体游动孢子。当不利的环境 条件来临时, 它开始有性生殖, 母细胞经过分裂, 产生配子(其形态结构与游动孢子相同, 但略小)。

配子被释放出来之后, 成对地进行融合, 每对配子 产生 1 个二倍体的合子，合子进一步特化为厚壁细 胞而进入休眠。当条件适宜时, 合子萌发, 通过减 数分裂, 产生新的单倍体孢子, 待合子壁破裂后被 释放出来成为游动孢子。即在衣藻的生活史中, 单 倍体占据绝对优势，只有合子是二倍体。这种有性 生殖的产物一合子特化成形态结构上(与单倍体的 游动孢子)十分不同的厚壁狍子, 而这种厚壁狍子 具有能有效地抵御不良环境条件的能力。

另一个例子是在淡水中生活的一类小型无脊 椎动物水蚤(Daphnia) (隶属于甲壳纲)。在其生活史 中, 既能进行孤䧳生殖, 又能进行有性生殖(图10)。 水蚤在一年的大部分时期都进行孤雌生殖, 种群快 速增殖，只有当恶劣的环境条件(如食物不足等)来 临时, 才产出雄体(但比雌体小得多), 并与之交配, 形成休眠卵，休眠卵离开母体沉入湖底，等待萌发 的时机。休眠卵可以在环境中存活数年甚至更长时 间。

在陆地上生活的蚜虫(一种半翅目昆虫)亦是如 此。蚜虫在无性和有性生殖方式之间进行周期性切 换。在食物充裕的春季和夏季, 蚜虫进行孤雌生殖 (胎生), 后代几乎全为雌性, 导致种群快速的增长。 随着秋天的来临, 光周期和温度的变化预示着食物 数量的减少, 蚜虫开始转变为有性生殖(卵生), 这 时雌性蚜虫开始产出雄性幼虫, 并与之交尾, 然后 产出受精卵。受精卵在度过冬季后, 重新孵出雌性 蚜虫。而在温暖的环境(如热带或在温室)中, 只要食 物充裕, 蚜虫可以数年一直进行无性生殖。

辐足亚纲的原生动物(如太阳虫)一般进行二分 裂或出芽式的无性生殖, 当不利的环境条件来临 时, 形成狍囊并进行有性生殖: 首先伪足收缩, 体 表出现胶质复膜, 之后细胞分裂为两个子体 $(2 n)$, 并各自进行减数分裂(其中一个单倍体的核退化), 接着，在剩下的两个子体(n)间进行核融合和细胞质 融合, 形成接合子 $(2 \mathrm{n})$, 在厚的复膜中进入休眠, 等 待合适环境的来临再破膜而出，重新生出伪足，回 


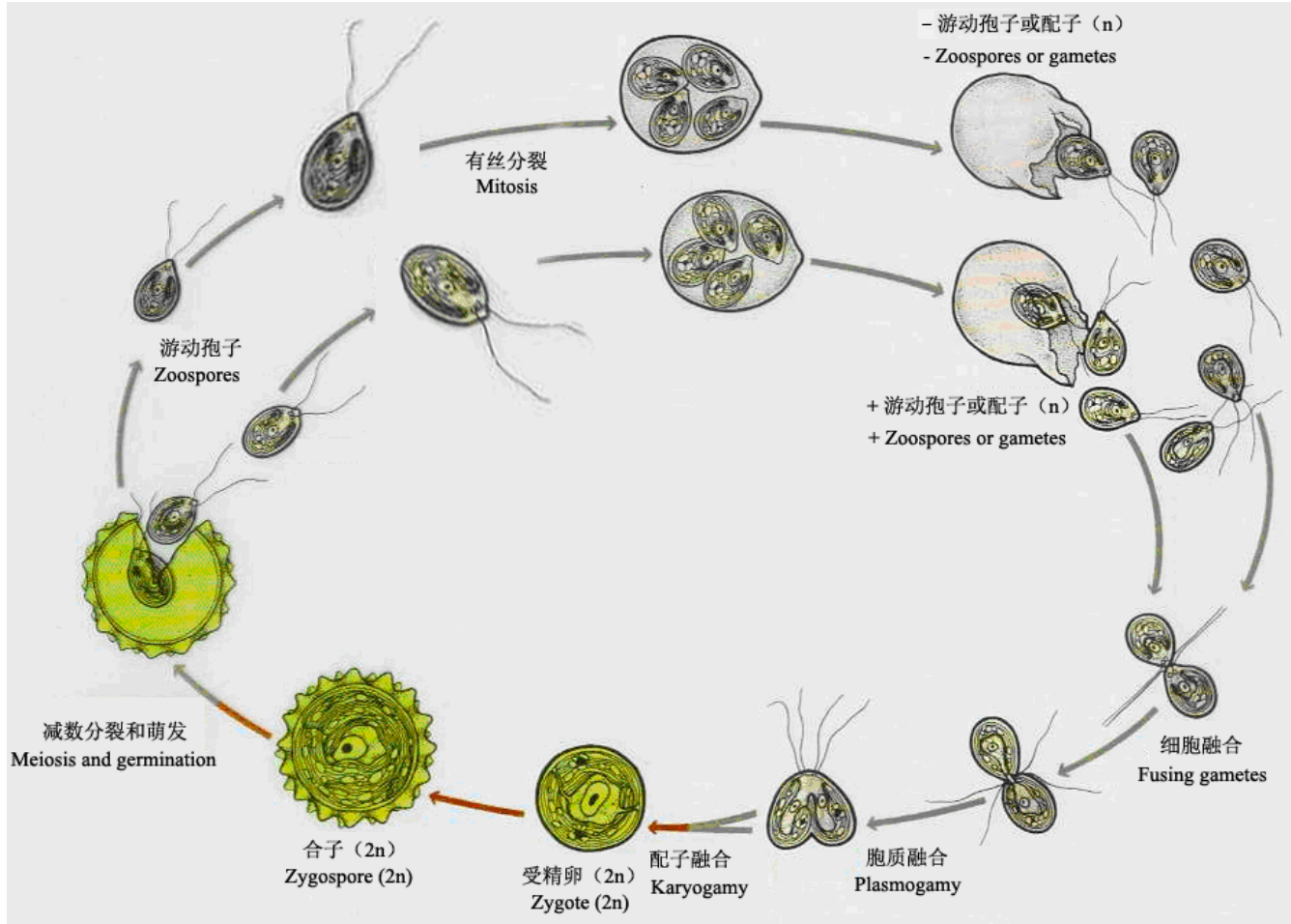

图9 绿藻一衣藻的生活史(引自 Raven et al, 1992)

Fig. 9 Life cycle of a green alga, Chlamydomonas (cited from Raven et al, 1992)

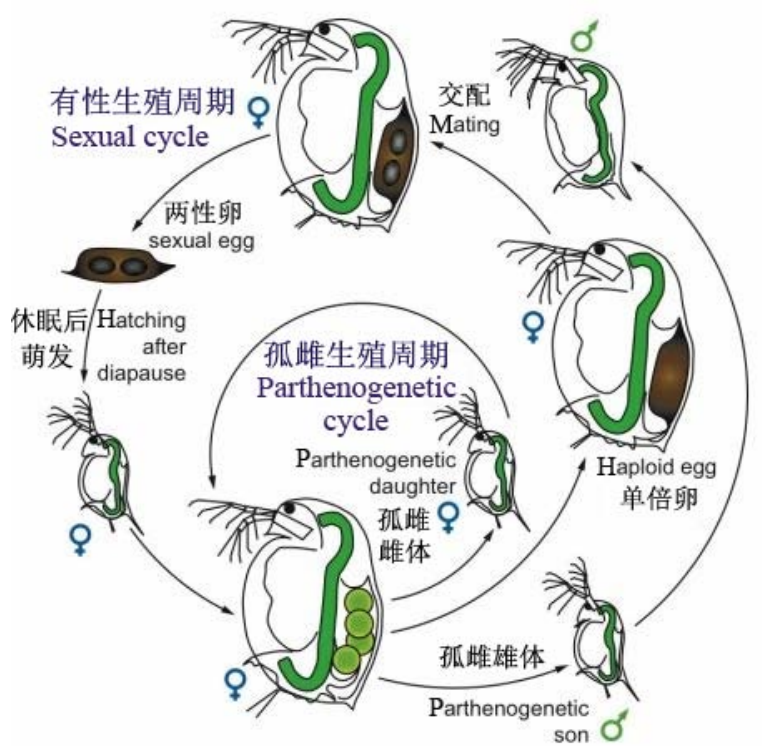

图10 周期性孤雌生殖水蚤的生活周期(仿Ebert, 2005)

Fig. 10 Life cycle of a cyclic parthenogenetic Daphnia (after Ebert, 2005)

到“光芒四射”的形态。太阳虫的孢囊具有多层壁， 表面覆盖着刺, 有利于其抵御不良的环境。太阳虫 的这种模式似乎介于绿藻与水蚤和蚜虫之间。
为了产休眠卵，像水蚤和蚜虫这样的无脊椎动 物, 孤雌生殖的雌体先产一些雄性个体出来, 再与 之交配，产下休眠卵。令人费解的是，这个行孤䧳 生殖的雌体为何不直接产一个休眠卵呢? 为何要 绕如此大的一个弯呢? 而这只能解释为一种遗留 的秉性一一不同细胞的DNA保持了在一定程度上 交流的特性, 从细菌那里就开始了, 只是它在之后 较为复杂的真核细胞那里, 偶然地与休眠联系起来 的。这就是为何笔者将此称之为休眠事件假说的缘 故。

对于很多生命周期不足一年的低等动植物来 说，通过休眠度过寒冷而食物贵乏的冬季是一种重 要的生存需求(当然, 一些动植物亦通过休眠来应 对干旱或高温季节)。“性”的动机原本是如此古朴, 但在进行胎生且生命周期“漫长”的哺乳动物那里却 失去了意义, 取而代之, “性”开始耦联绮丽、情趣、 愉悦......., 而如果(事实上是)沉湎于此等衍生之物, 何以能寻受到“性”的开端?

\section{参考文献}

Bell G (1982) The Masterpiece of Nature: the Evolution and Genetics of Sexuality. University of California Press, 
Berkeley.

Bell PJ (2001) Viral eukaryogenesis: was the ancestor of the nucleus a complex DNA virus? Journal of Molecular Evolution, 53, 251-256.

Campbell NA, Reece JB (2008) Biology, 8th edn. Benjamin Cummings, San Francisco.

Coyne JA (2009) Why Evolution is True. Viking Penguin, New York David LA, Alm EJ (2011) Rapid evolutionary innovation during an Archaean genetic expansion. Nature, 469, 93-96.

de Roos AD (2006) The origin of the eukaryotic cell based on conservation of existing interfaces. Artificial Life, 12, 513-523.

Ebert D (2005) Ecology, Epidemiology, and Evolution of Parasitism in Daphnia. National Library of Medicine (US), National Center for Biotechnology Information, Bethesda, MD.

Fuerst JA (2005) Intracellular compartmentation in planctomycetes. Annual Review of Microbiology, 59, 299-328.

Gregory TR (2004) Macroevolution, hierarchy theory, and the C-value enigma. Paleobiology, 30, 179-202.

Hadany L, Comeron JM (2008) Why are sex and recombination so common? Annals of the New York Academy of Sciences, 1133, 26-43.

Hogan CM (2010) Archaea. In: Encyclopedia of Earth (eds Monosson E, Cleveland C). National Council for Science and the Environment, Washington, DC.

Jacob F (1998) Of Flies, Mice and Men (translated from the French edition). Harvard University Press, Cambridge MA.

Koonin EV (2015) Origin of eukaryotes from within archaea, archaeal eukaryome and bursts of gene gain: eukaryogenesis just made easier? Philosophical Transactions of the Royal Society B, 370, 20140333.

Margulis L (1981) Symbiosis in Cell Evolution, pp. 206-227. W. H. Freeman and Company, San Francisco.

Martin WF, Garg S, Zimorski V (2015) Endosymbiotic theories for eukaryote origin. Philosophical Transactions of the Royal Society B, 370, 20140330.

McInerney J, Pisani D, O'Connell MJ (2015) The ring of life hypothesis for eukaryote origins is supported by multiple kinds of data. Philosophical Transactions of the Royal Soci- ety B, 370, 20140323

Mereschkowsky K (1910) Theorie der zwei Plasmaarten als Grundlage der Symbiogenesis, einer neuen Lehre von der Entstehung der Organismen. Biologisches Centralblatt 30, 353-367.

Moreira D, López-García P (2015) Evolution of viruses and cells: do we need a fourth domain of life to explain the origin of eukaryotes? Philosophical Transactions of the Royal Society B, 370, 20140327.

Pennisi E (2004) Evolutionary biology. The birth of the nucleus. Science, 305, 766-768.

Prescott DM (1994) The DNA of ciliated protozoa. Microbiological Reviews, 58, 233-267.

Raven PH, Evert RF, Eichhorn SE (1992) Biology of Plants, 5th edn. Worth Publishers, New York.

Schurko AM, Neiman M, Logsdon JM Jr (2008) Signs of sex: what we know and how we know it. Trends in Ecology \& Evolution, 24, 208-217.

Takemura M (2001) Poxviruses and the origin of the eukaryotic nucleus. Journal of Molecular Evolution, 52, 419-442.

Villarreal L, DeFilippis V (2000) A hypothesis for DNA viruses as the origin of eukaryotic replication proteins. Journal of Virology, 74, 7079-7084.

Wallin IE (1923) The mitochondria problem. The American Naturalist, 57, 255-261.

Xie P (2013) Scaling Ecology to Understand Natural Design of Life Systems and Their Operations and Evolutions-Integration of Ecology, Genetics and Evolution Through Reproduction. Science Press, Beijing. [谢平 (2013) 从生态学透视生命系统的设计、运作与演化 生态、遗传和进化通过生殖的融合. 科学出版社, 北京.]

Xie P (2014) The Aufhebung and Breakthrough of the Theories on the Origin and Evolution of Life-Life in Philosophy and Philosophy in Life Sciences. Science Press, Beijing. [谢平 (2014) 生命的起源一进化理论之扬弃与革新一一哲学中 的生命, 生命中的哲学. 科学出版社, 北京.]

Zimmer C (2009) On the origin of sexual reproduction. Science, 324, 1254-1256. 